\title{
Fragility fracture prevalence among elderly Chinese is no more than half of that of elderly Caucasians
}

\author{
Yì Xiáng J. Wáng^ \\ Department of Imaging and Interventional Radiology, Faculty of Medicine, The Chinese University of Hong Kong, Hong Kong, China \\ Correspondence to: Dr. Yì Xiáng J. Wáng. Department of Imaging and Interventional Radiology, Faculty of Medicine, The Chinese University of \\ Hong Kong, Hong Kong, China. Email: yixiang_wang@cuhk.edu.hk.
}

Submitted Sep 01, 2021. Accepted for publication Nov 15, 2021.

doi: 10.21037 /qims-21-876

View this article at: https://dx.doi.org/10.21037/qims-21-876

Fragility (osteoporotic) fracture prevalence difference among various ethnic groups has been well noted. In this editorial, I summarize the evidence that fragility fracture prevalence among elderly Chinese is no more than half of that of elderly Caucasians. I have systematically searched and read relevant literature. However, the current editorial is not a systematic review. There are reports with conflicting results, it is not reasonable to simply synthesise them together. It can be noted that some reports are limited by sampling bias and small sample size. I primarily review original reports where Chinese and Caucasians were compared in the same study. This will allow a more direct comparison of risk factors and be less affected by methodological differences. This editorial reflects my personal interpretation of the published data, which is expected also to reflect the mainstream conclusion of most reports. For the reports from the USA, an important limitation is that Chinese is often grouped under the category of 'Asians'. As there are some highquality comparative studies conducted between Caucasians and Japanese, I also use some of these data to support my arguments for the risks associated with the elderly Chinese population.

\section{Hip fragility fracture}

Hip fracture is the most important fragility fracture. Among all osteoporotic fractures, hip fracture incurs the greatest morbidity, mortality, and costs. Hip fracture typically requires hospitalization, making hip fracture incidence ascertainment more reliable than for other types of fractures.

With a database of all hospitalizations for the State of California, Silverman and Madison (1) in 1987 examined the incidence of hip fracture in Caucasians (non-Hispanic White) and Asian Americans for the years 1983 and 1984. They reported the Asian American populations in California had rate ratios of hip fracture relative to Caucasians of 0.61 for women and 0.54 for men.

In 1993 Ho et al. (2) examined the hospital discharge data for hip fracture in Hong Kong and in the USA for 1988 through 1989. Hong Kong data were obtained from six government hospitals and three government-assisted hospitals. The USA data were obtained from the National Hospital Discharge Survey. Incidence rates of hip fracture for the 2-year interval were calculated for men and women (Figure 1). The age-adjusted fracture rates per 100,000 were significantly lower in Hong Kong than in the USA for men (100 vs. 187, ratio: 0.53 ) and women (247 vs. 535, ratio: $0.46)$. Ho et al. (2) concluded that hip fracture rates in the USA were typically 1.5 to 2.5 times those in Hong Kong across the age and sex groups.

In 1996 Lauderdale et al. (3) estimated US national ageand sex-specific nontraumatic hip fracture incidence rates for elderly Chinese Americans, Japanese Americans, and Korean Americans (all $\geq 65$ years). Based on a $50 \%$ sample of 1992 Medicare enrollees, cohorts of persons with distinctive Chinese $(n=24,366)$, Japanese $(n=28,762)$, and Korean

\footnotetext{
$\wedge$ ORCID: 0000-0001-5697-0717.
} 

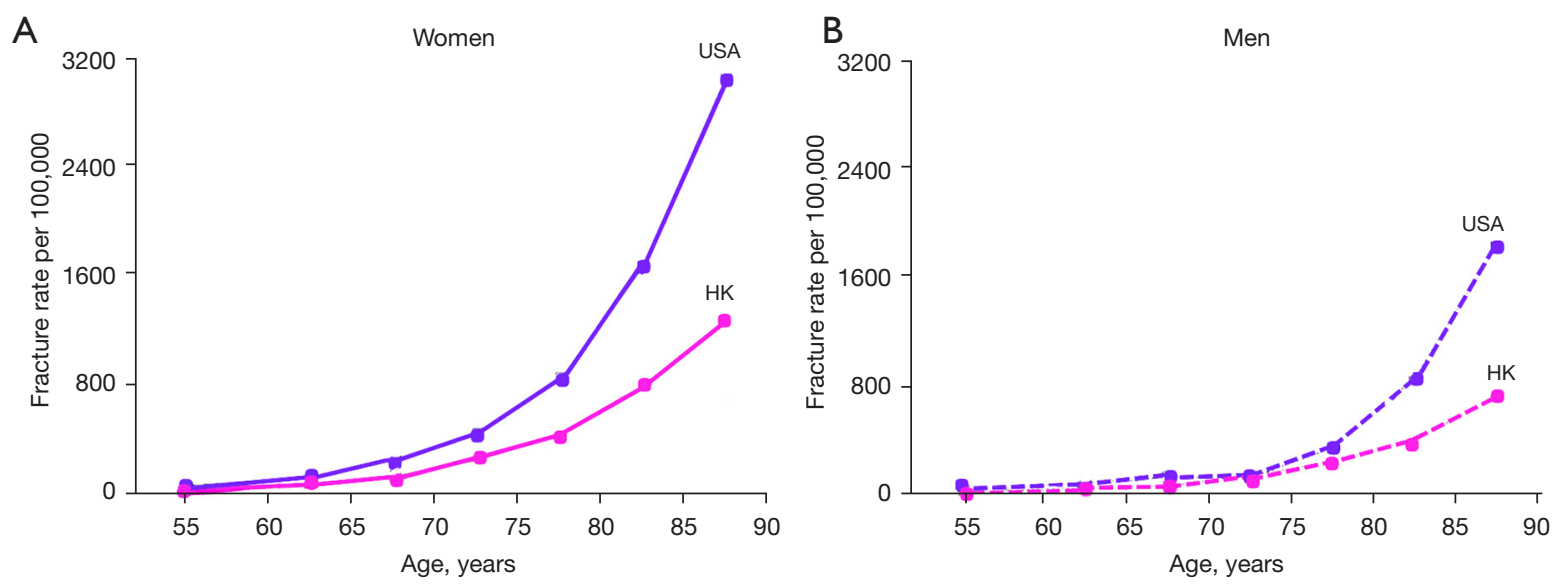

Figure 1 Hip fracture rate among Hong Kong and USA elderly populations. Adapted from Ho et al. (2).

$(\mathrm{n}=5,470)$ names were followed passively for two years for hospitalization with a diagnostic code indicating hip fracture. Cohorts of Caucasians (10\% sample) were followed for comparison. They reported that age-adjusted hip fracture incidence was lower for all three East AsianAmerican groups than for Caucasians, with the fracture ratio relative to Caucasians being 0.30 for Chinese women and 0.42 for Chinese men.

In 2003 Zingmond et al. (4) evaluated the change in standardized hip fracture incidence from 1983 through 2000 in California Hispanics relative to other racial groups. With Caucasians' rate as the reference, the hip fracture rate was approximately 0.5 for Asian women, and 0.4 for Asian men.

In 2004, Fang et al. (5) analysed the hip fracture hospitalization rates for Asian and Caucasian patients aged 50 and older in New York City from 1988 to 2002. They reported annual age-adjusted hip fracture hospitalization rates per 100,000 among Asian women and Caucasian women were 174 and 459 respectively (Asian vs. Caucasian ratio: 0.379$)$; and the corresponding rates for men were 104 and 230 respectively (ratio: 0.452 ).

In 2011, with a comparison made with their own data (2,302 women and 1,810 men) and published Japanese and Swedish data, Bow et al. (6) reported that Japanese and Hong Kong Chinese had a very similar age-specific hip fragility fracture prevalence; while the hip fracture rates for Hong Kong men and women aged 65 to 69 years old were $49 \%$ and $33 \%$ of those of Caucasian men and women in the same age group.

In 2012 Wright et al. (7) investigated hip fracture incidence trends in ethnic subgroups of older Medicare beneficiaries ( $\geq 65$ years old) and analysed annual hip fracture incidence rates from 2000 through 2009. They reported that, for both elderly men and women, Asians had approximately half of hip fracture incidence of those of Caucasians.

By analysing the Canadian population-based Manitoba bone mineral density (BMD) Program registry data, in 2021 Leslie et al. (8) reported a study that included 68,907 Caucasian women (mean age: $64.7 \pm 10.9$ years) and 1,910 Asian women (mostly Chinese and Filipino, mean age: $62.8 \pm 9.9$ years). During a follow-up period of $8.8 \pm 5.1$ years for Caucasians and 6.5 \pm 5.0 years for Asians, incident hip fracture rate per 1,000 person-years was $0.6[95 \%$ confidence interval (CI): 0.2-1.0] for Asians and 3.6 (95\% CI: 3.5-3.8) for Caucasians (Asian vs. Caucasian ratio: 0.17).

For Japanese data, by analysing hospital records, in 1991 Ross et al. (9) described hip fracture incidence rates from 1979 to 1981 among men and women (ages 50-84 years) of Japanese ancestry living in Hawaii and compared with hip fracture incidence rates from 1984 to 1985 among Japanese living on Okinawa, Japan. Both rates were further compared with those from 1978 to 1982 among American Caucasians of Rochester, MN, USA. The standardized rate of hip fracture among women of Hawaii Japanese and Okinawa were both 0.48 (95\% CI: $0.38-0.60$ and $0.41-0.57$ ) of the value for Caucasian women. The standardized rates of hip fracture among men of Hawaii Japanese and Okinawa Japanese were 0.33 (95\% CI: 0.21-0.50) and 0.32 (95\% CI: $0.23-0.45)$ of the value for Caucasian men. It was noted that, although the diet and other cultural attributes of the Hawaii Japanese were more westernized than the Okinawan population, there were no detectable differences in hip 

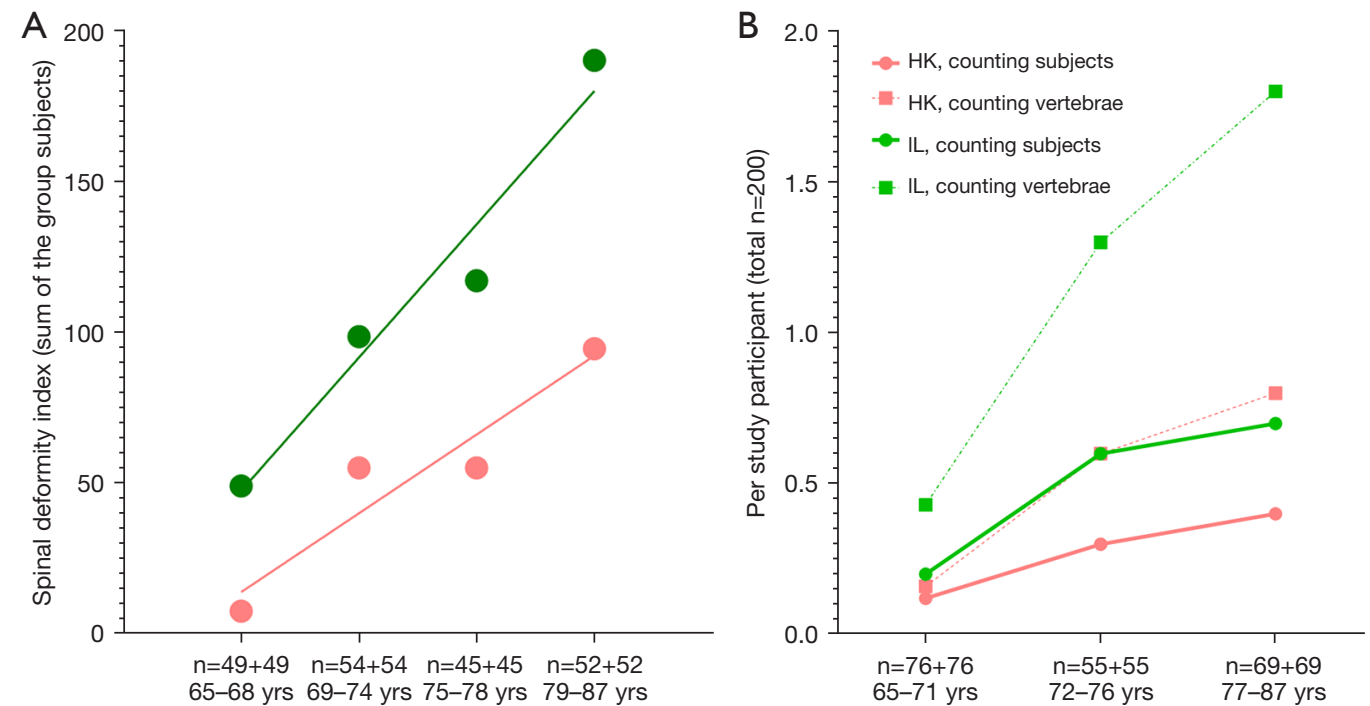

Figure 2 A comparison of Hong Kong Chinese women and Italian Caucasian women OVF prevalence and severity (both mean age: 74.1 years). (A) Spinal deformity index score (product of the number of vertebrae with OVF and their grading) of four different age groups of Chinese and Italian women. (B) Prevalence of vertebral ECF among three different age groups. Solid lines represent the number of ECF subjects divided by the number of subjects in each age group. Dotted lines represent the number of ECF vertebrae divided by the number of subjects in each age group. Light red lines indicate Chinese subjects and green lines indicate Italian subjects. $\mathrm{N}=49+49$ means there are 49 Chinese subjects and 49 Italian subjects in this age group. Reproduced with permission from (12). OVF, osteoporotic vertebral fracture; ECF, endplate and/or cortex fracture.

fracture rates between Hawaii ethnic Japanese and Okinawa Japanese.

\section{Vertebral fragility fracture}

Many earlier studies reported that, compared with those of Caucasians, East Asians' prevalence of radiographic osteoporotic vertebral fracture (OVF) was similar or even higher $(6,10)$. However, these results are likely due to methodological imperfections. Recent evidence suggests that, compared with Caucasians, the relative prevalence of OVF follows the same pattern as other clinical fractures.

In 2012 Kwok et al. (11) estimated that OVF prevalence in Chinese women is similar to those of Japanese, Korean, and Latin Americans, but lower than those of age-matched European and American Caucasian women. It is interesting to note that it has been demonstrated in many USA studies that Asian Americans have a hip fragility prevalence similar to that of Hispanics $(4,5,7)$. However, the results of Kwok et al. (11) were derived with various criteria for defining radiographic OVF.

With spine radiographs from two epidemiological studies conducted in Hong Kong and in Rome, a recent study compared OVF prevalence in age-matched elderly Chinese women and Italian Caucasian women (both mean age: 74.1 years). The results show Hong Kong Chinese subjects had endplate and/or cortex OVF (ECF) in 26\% cases involving $3.54 \%$ of the vertebrae, while Italian subjects had ECF in $47 \%$ cases involving $8.21 \%$ of the vertebrae; $9.5 \%$ Chinese women and $26 \%$ Italian women had OVF with $\geq 40 \%$ height loss (12). OVF in Italian subjects tended to be more severe, more likely to be multiple. A trend suggested an earlier onset of OVF among Italian women (Figure 2).

In MrOS (Hong Kong) and MsOS (Hong Kong) studies, from baseline on, clinical spine fractures (mostly fragility fractures) were followed-up for 10 years for 1,954 male participants, and for 9 years for 1,953 female participants. Clinical spine fracture $\geq 1$ time (i.e., at least one fracture incident) were recorded 133 cases and 273 cases per 100,000 person-years in men and women, respectively (13). In MrOS (USA) study which had the same enrolment strategy for participants as MrOS (Hong Kong) study, with 5,995 cases followed up for 4.7 years, Freitas et al. (14) recorded clinical spine fracture incidence of 216 cases/100,000 person-years. Note that, at the end of these follow-ups, MrOS (Hong Kong) subjects were older 
than the USA subjects. Moreover, for the population-based study in Rochester, MN, USA, for the 5-year study period of 1985-1989, Cooper et al. (15) estimated clinical vertebral fracture incidences with moderate trauma of 238 for men and 975 for women per 100,000 person-years for the age group of 75-84 years, which is much higher than the MrOS (Hong Kong) and MsOS (Hong Kong) rates. However, the study of Cooper et al. (15) is limited by its small sample size for the elderly subjects.

To support the discussion above that Chinese have a lower OVF prevalence than that of Caucasians, for the MrOS (Hong Kong) year-4 follow-up study, with 1,500 elderly Hong Kong Chinese men followed up for four years, participants with baseline OVF had little increased risk for further OVF $(16,17)$. This result differs from Caucasian studies on men where participants with baseline OVF had an increased risk for further OVF $(18,19)$. Moreover, all related reports suggest that, compared with Caucasians, Asians and Chinese in particular have a lower incident rate of back pain. Mailis-Gagnon et al. (20) collected data on new patients over a three-year period at the Comprehensive Pain Program (CPP) in downtown Toronto. They noted the East Asian group (primarily Chinese) was the most underrepresented (1.6\% of the CPP population), despite that this group accounted for $9 \%$ of the population in Toronto and $6.01 \%$ of the Greater Toronto Area population. Waterman et al. (21) analysed the National Electronic Injury Surveillance System (USA) for all cases of low back pain presenting to emergency departments between 2004 and 2008. They found that the per 1,000 person-years low back pain incident rates were 1.23 among whites, while only 0.20 among Asians.

\section{General fragility fractures}

By analysing the data from the National Osteoporosis Risk Assessment (NORA) which is an observational study of postmenopausal women in the USA, in 2005 BarrettConnor et al. (22) reported the baseline characteristics and 1-year fracture incidents in Caucasians and Asians. At baseline, among 179,470 Caucasians, $23.3 \%$ had a maternal history of fracture, and a history of any fracture at age 45 years or older was recorded in $11.2 \%$ of cases; among 1,912 Asians, $11.6 \%$ had a maternal history of facture, and a history of fracture since 45 years old was recorded in $7.2 \%$ of the cases. During the follow-up, a fracture at any location was recorded in $1.5 \%$ of 149,524 Caucasians and in $0.7 \%$ of 1,258 Asians. They noted that, after adjusting for BMD, weight, and other covariates, with Caucasian women as the referent group (relative risk: 1.0), Asian American women had a relative risk of 0.32 (95\% CI: 0.15-0.66) for fracture.

With cross-sectional analysis of the datasets of the Osteoporotic Fractures in Men Study [MrOS (USA), $\mathrm{n}=5,342$ Caucasians], MrOS Hong Kong $(\mathrm{n}=1,968)$, Namwon Study and Dong-gu study in Korea $(\mathrm{n}=3,891)$, in 2014 Shin et al. (23) reported the prevalence of selfreported non-traumatic fracture for men aged 65 years and older was US white $17.1 \%$, US Asian $10.5 \%$, Hong Kong Chinese 5.6\%, and Korean 5.1\%.

Analysing the Canadian Multicentre Osteoporosis Study (CaMos) data, in 2020 Morin et al. (24) compared the prevalence of low-trauma fractures between Chinese and Caucasian participants at the time of recruitment into the cohort, and 5-year incident fractures between the two groups. At baseline, the mean age was $63.2( \pm 8.7)$ and 67.0 $( \pm 7.1)$ years for Chinese $(\mathrm{n}=104)$ and Caucasian women $(\mathrm{n}=5,361)$; the mean age was $67.0( \pm 9.0)$ and $66.4( \pm 9.5)$ years for Chinese $(n=74)$ and Caucasian men $(n=2,044)$. Any low trauma fracture history was recorded in $7.7 \%$ of the Chinese women, while in $22.2 \%$ of the Caucasian women; and recorded in $6.8 \%$ of the Chinese men and $17.2 \%$ of the Caucasian men. For the 5 -year incident fracture, $6.4 \%$ of Chinese women reported any incident fractures compared with $7.8 \%$ in Caucasian women; $3.0 \%$ of Chinese men reported any incident fractures compared with $4.1 \%$ any incident fractures in Caucasian men. In the meantime, Morin et al. (24) noted that the comparisons between the incident fractures between Chinese and Caucasians were inconclusive due to the small numbers of events.

In 2021, by analysing the above-mentioned Manitoba BMD Program registry data, Leslie et al. (8) reported that, at baseline prior fracture history was recorded in $20.1 \%$ of the Caucasian women (total included $n=68,907$, mean age: $64.7 \pm 10.9$ years) and $11.7 \%$ of the Asian women (total: $\mathrm{n}=1,910$, mostly Chinese and Filipino, mean age: $62.8 \pm 9.9$ years). During the follow-up of $8.8 \pm 5.1$ years for Caucasians and $6.5 \pm 5.0$ years for Asians, the incident rate for major osteoporotic fracture (MOF; a composite of hip, humerus, forearm, and clinical vertebral fractures) per 1,000 person-years was 11.4 (95\% CI: 11.2-11.7) for Caucasians and 5.0 (95\% CI: 3.8-6.2) for Asians. They noted that, with adjustment for baseline risk using the Canadian FRAX tool with $\mathrm{BMD}$, Asian women compared with Caucasian women were at much lower risk for MOF (hazard ratio $=0.46 ; 95 \%$ CI: $0.35-0.59$ ) and hip fracture (hazard ratio $=0.16,95 \%$ CI: 0.08-0.34). 


\section{Bone mass decline rate}

There is evidence that elderly East Asians lose bone mass more slowly than Caucasians. In 1998 Dennison et al. (25) published a study on bone loss rate in a British cohort and a Japanese cohort. Bone loss rates by BMD measure were obtained for 172 Hertfordshire (UK) men (mean age: 66 years) and 143 Hertfordshire women (mean age: 65.6 years). The follow-up study was performed 4 years after the baseline measure. Eighty-six Japanese men (mean age: 68.7 years) and 90 Japanese women (mean age: 69.3 years) completed a similar study in Taiji, Japan. The follow-up study was performed 3 years after the baseline measure. For British subjects, the estimated femoral neck annual bone loss was $0.36 \pm 1.98 \%$ in men and $1.05 \% \pm 1.54 \%$ in women; estimated trochanter annual bone loss was $0.20 \% \pm 1.23 \%$ in men and $1.43 \% \pm 1.33 \%$ in women. For Japanese subjects, the estimated femoral neck annual bone change was an increase of $0.33 \% \pm 2.22 \%$ in men and an increase of $0.14 \% \pm 2.11 \%$ in women; estimated trochanter annual bone change was an increase of $0.59 \% \pm 1.57 \%$ in men, and a loss of $0.20 \% \pm 1.71 \%$ in women. The gain in BMD during follow-up among Japanese subjects was not well explained, but it could be associated with osteoarthritis (25).

In 2011 Sheu et al. (26) reported a USA-based study with an average follow-up of 4.6 years in 3,869 Caucasian men and 145 Asian men aged $\geq 65$ years (mean ages: $73 \pm 5$ and $72 \pm 5$ years, respectively). The annual rate of decline in BMD at the femoral neck was $0.32 \%$ and $0.09 \%$ /year respectively for Caucasians and American Asians. They conclude that Asian men experience a slower rate of decline in BMD compared with Caucasians.

With the CaMos data and comparing Caucasian Canadian and Chinese Canadian, in 2020 Morin et al. (24) reported that during a 5-year period Chinese lost less bone mass than Caucasian men and women. For the participants aged $>50$ years, 5-year BMD change $\left(\mathrm{g} / \mathrm{cm}^{2}\right)$ was -0.002 and -0.000 for Chinese women femoral neck and total hip, while was -0.011 and -0.013 for Caucasian women femoral neck and total hip. Five-year BMD change $\left(\mathrm{g} / \mathrm{cm}^{2}\right)$ was -0.005 and -0.003 for Chinese men femoral neck and total hip, while -0.011 and -0.013 for Caucasian men femoral neck and total hip.

The current editorial is more focused on the reports from North America. It can be argued that the most reliable comparative studies are those where two ethnic groups were compared by the same investigators and using the same criteria or methods. While fragility fracture prevalence is certainly influenced by a combination of genetic and environmental/lifestyle factors, if only Chinese in North America and Caucasians in North America are compared, then environmental and lifestyle for the Chinese living in China would not be fully counted. However, I argue that it is the biological risk factors that dominate. For example, Hong Kong Chinese and Chinese in the USA both have a hip fracture prevalence of no more than half of that of Caucasians. Ross et al. (9) described that, although the lifestyle of the Hawaii Japanese is more westernized than Okinawa Japanese, the hip fracture rates of Hawaii Japanese and Okinawa Japanese are almost the same.

The three East Asian ethnic groups, i.e., Chinese, Japanese, and Korean, are under the same category of 'Asians' in most of the USA reports. A detailed comparison of fragility fracture prevalence among these three East Asian ethnic groups is beyond the scope of this editorial. However, I take the working assumption that the fragility fracture prevalence of these three East Asian ethnic groups is broadly similar. Bow et al. (6) reported that Japanese and Hong Kong Chinese have very similar age-specific hip fragility fracture prevalence. Shin et al. (23) reported the prevalence of self-reported non-traumatic fracture for men aged 65 years and older was Hong Kong Chinese $5.6 \%$, and Korean 5.1\%. Kwok et al. (11) estimated OVF in Chinese women is very similar to those of age-matched Japanese, Korean. Lau et al. (27) analysed the Hong Kong and Singapore hospitals' hip fracture discharge data for the year 1997. For the patients who were 50 years of age and older, they noted that the age-adjusted incident rates (per 100,000) for men and women were: Hong Kong 180 and 459; Singapore, 164 and 442; thus being quite similar.

For the reports cited in this editorial, fragility fracture prevalence among elderly Chinese is mostly no more than $50 \%$ of that of Caucasians, and much lower rates (such as $30 \%$ of that of Caucasians) have also been reported. A much slower bone mass decline rate among elderly Chinese may at least partially contribute to their lower fragility fracture prevalence. Based on the evidence presented in this editorial, it may be a reasonable summary that fragility fracture prevalence among elderly Chinese is probably $40 \%$ of that of age-matched Caucasians, which is the same both for women and for men. It has been reported that hip fragility fracture prevalence in Taiwan is substantially higher than those in other East Asian Territories (28). Since the population in Taiwan is not ethnically distinct, the reported higher hip fragility fracture prevalence in Taiwan could be either due to (I) study artefacts (more likely so), or 
(II) some kinds of unique lifestyle factors. The actual cause for this discrepancy should be further clarified. The review by Ballane et al. (29) described very heterogeneous OVF prevalence among various ethnic groups in East Asia and Southeast Asia, it is highly probable that the observed OVF prevalence differences were more due to methodological imperfections than genuine biological differences.

The discussions in this editorial will be relevant for estimating the osteoporosis burden for Chinese and setting the BMD threshold for defining osteoporosis status among Chinese (30). Moreover, evidence suggests that, for both Chinese and Caucasians, the prevalence of hip fragility fractures in elderly women is approximately twice that of elderly men. The review by Rapp et al. (31) concluded, that the age-standardized difference of hip fragility fracture prevalence between women and men has a ratio of about 2:1 in most countries of the world. In the middle East, a recent study based on the Lebanese ministry of public health hip fracture registry, spanning from 2006 to 2017, reported a total of 6,985 hip fractures. The mean hip fracture incident over the 12-year period was $162 / 100,000$ in women and $91 / 100,000$ in men, with a women/men incidence rate ratio of 1.78 (32). Based on a large national in-patients database, Gong et al. (33) assessed hip fracture incidence in seven geographical regions of China, which involved 238,230 hip fracture patients aged 65 years or older from 2013 to 2016, and reported a women/men incidence rate ratio of 1.95 . In Western countries it can be that approximately three out of four hip fractures occur in women. This huge difference in the absolute number of fractures is partly explained by the greater life expectancy of women (34). The populationbased Dubbo study in Australia study documents the incidence of all symptomatic fractures from 1989 to 1992 in a predominantly Caucasian population ( $\geq 60$ years). The overall fracture incidence in women was 3,250 per 100,000 person-years and in men was 1,940 per 100,000 personyears $(1.67: 1)$. It is estimated that residual lifetime fracture risk in a person aged 60 years with average life expectancy was $29 \%$ for men and $56 \%$ for women (35). In our MrOS (Hong Kong) and MsOS (Hong Kong) year-4 follow-up studies, radiographic OVF incidences occurs in $2.13 \%$ of the men and $6.46 \%$ of the women $(16,36)$. Following the WHO definitions of osteoporosis and T-score $(37,38)$, T-score threshold for defining osteoporosis in men should be adjusted so that osteoporosis prevalence in elderly men should be approximately half, or to some extent less than half, of that of elderly women.

In conclusion, this editorial emphasizes the importance of considering ethnicity on bone health assessment. Knowing that fragility fracture prevalence among elderly Chinese is less than half of that of elderly Caucasians will have important implications in diagnostic criteria setting-up for osteoporosis disease category and in cost-effectiveness assessment for treatment interventions.

\section{Acknowledgments}

Funding: None.

\section{Footnote}

Provenance and Peer Review: This article was a standard submission to the journal. The article has undergone external peer review.

Conflicts of Interest: The author has completed the ICMJE uniform disclosure form (available at https://dx.doi. org/10.21037/qims-21-876). YXJW serves as the Editor-InChief of Quantitative Imaging in Medicine and Surgery and has no other conflicts of interest to declare.

Ethical Statement: The author is accountable for all aspects of the work in ensuring that questions related to the accuracy or integrity of any part of the work are appropriately investigated and resolved.

Open Access Statement: This is an Open Access article distributed in accordance with the Creative Commons Attribution-NonCommercial-NoDerivs 4.0 International License (CC BY-NC-ND 4.0), which permits the noncommercial replication and distribution of the article with the strict provision that no changes or edits are made and the original work is properly cited (including links to both the formal publication through the relevant DOI and the license). See: https://creativecommons.org/licenses/by-nc-nd/4.0/.

\section{References}

1. Silverman SL, Madison RE. Decreased incidence of hip fracture in Hispanics, Asians, and blacks: California Hospital Discharge Data. Am J Public Health 1988;78:1482-3.

2. Ho SC, Bacon WE, Harris T, Looker A, Maggi S. Hip fracture rates in Hong Kong and the United States, 1988 through 1989. Am J Public Health 1993;83:694-7.

3. Lauderdale DS, Jacobsen SJ, Furner SE, Levy PS, 
Brody JA, Goldberg J. Hip fracture incidence among elderly Asian-American populations. Am J Epidemiol 1997;146:502-9.

4. Zingmond DS, Melton LJ 3rd, Silverman SL. Increasing hip fracture incidence in California Hispanics, 1983 to 2000. Osteoporos Int 2004;15:603-10.

5. Fang J, Freeman R, Jeganathan R, Alderman MH. Variations in hip fracture hospitalization rates among different race/ethnicity groups in New York City. Ethn Dis 2004;14:280-4.

6. Bow CH, Cheung E, Cheung CL, Xiao SM, Loong C, Soong C, Tan KC, Luckey MM, Cauley JA, Fujiwara S, Kung AW. Ethnic difference of clinical vertebral fracture risk. Osteoporos Int 2012;23:879-85.

7. Wright NC, Saag KG, Curtis JR, Smith WK, Kilgore ML, Morrisey MA, Yun H, Zhang J, Delzell ES. Recent trends in hip fracture rates by race/ethnicity among older US adults. J Bone Miner Res 2012;27:2325-32.

8. Leslie WD, Morin SN, Lix LM, McCloskey EV, Johansson H, Harvey NC, Kanis JA. Fracture prediction from FRAX for Canadian ethnic groups: a registry-based cohort study. Osteoporos Int 2021;32:113-22.

9. Ross PD, Norimatsu H, Davis JW, Yano K, Wasnich RD, Fujiwara S, Hosoda Y, Melton LJ 3rd. A comparison of hip fracture incidence among native Japanese, Japanese Americans, and American Caucasians. Am J Epidemiol 1991;133:801-9.

10. Kung AW. Epidemiology and diagnostic approaches to vertebral fractures in Asia. J Bone Miner Metab 2004;22:170-5.

11. Kwok AW, Gong JS, Wang YX, Leung JC, Kwok T, Griffith JF, Leung PC. Prevalence and risk factors of radiographic vertebral fractures in elderly Chinese men and women: results of Mr. OS (Hong Kong) and Ms. OS (Hong Kong) studies. Osteoporos Int 2013;24:877-85.

12. Wáng YXJ, Diacinti D, Leung JC, Iannacone A, Kripa E, Kwok TC, Diacinti D. Much lower prevalence and severity of radiographic osteoporotic vertebral fracture in elderly Hong Kong Chinese women than in age-matched Rome Caucasian women: a cross-sectional study. Arch Osteoporos 2021;16:174.

13. Su Y, Wáng YXJ, Kwok TC. The predictive power of vertebral endplate/cortical fracture (ECF) for further osteoporotic fracture risk among community dwelling elderly Chinese. The 11th meeting of Chinese Society of Osteoporosis and Bone Mineral Research, 2020.

14. Freitas SS, Barrett-Connor E, Ensrud KE, Fink HA, Bauer DC, Cawthon PM, Lambert LC, Orwoll ES; Osteoporotic
Fractures in Men (MrOS) Research Group. Rate and circumstances of clinical vertebral fractures in older men. Osteoporos Int 2008;19:615-23.

15. Cooper C, Atkinson EJ, O'Fallon WM, Melton LJ 3rd. Incidence of clinically diagnosed vertebral fractures: a population-based study in Rochester, Minnesota, 19851989. J Bone Miner Res 1992;7:221-7.

16. Wáng YXJ, Che-Nordin N, Deng M, Griffith JF, Leung JCS, Kwok AWL, Leung PC, Kwok TCY. Elderly males with or without existing osteoporotic vertebral fracture have much lower future vertebral fracture risk than elderly females: the MrOS (Hong Kong) year-4 follow-up spine radiograph study. Osteoporos Int 2019;30:2505-14.

17. Wáng YXJ, Che-Nordin N, Leung JCS, Kwok TCY. Existing severe osteoporotic vertebral fractures in elderly Chinese males were only weakly associated with higher further vertebral fracture risk at year-4 follow-up. Osteoporos Int 2020;31:1593-4.

18. Karlsson MK, Kherad M, Hasserius R, Nilsson JÅ, Redlund-Johnell I, Ohlsson C, Lorentzon M, Mellström D, Rosengren BE. Characteristics of Prevalent Vertebral Fractures Predict New Fractures in Elderly Men. J Bone Joint Surg Am 2016;98:379-85.

19. Lentle BC, Berger C, Brown JP, Probyn L, Langsetmo L, Hammond I, Hu J, Leslie WD, Prior JC, Hanley DA, Adachi JD, Josse RG, Cheung AM, Kaiser SM, Towheed T, Kovacs CS, Wong AKO, Goltzman D. Vertebral Fractures: Which Radiological Criteria Are Better Associated With the Clinical Course of Osteoporosis? Can Assoc Radiol J 2021;72:150-8.

20. Mailis-Gagnon A, Yegneswaran B, Nicholson K, Lakha SF, Papagapiou M, Steiman AJ, Ng D, Cohodarevic T, Umana M, Zurowski M. Ethnocultural and sex characteristics of patients attending a tertiary care pain clinic in Toronto, Ontario. Pain Res Manag 2007;12:100-6.

21. Waterman BR, Belmont PJ Jr, Schoenfeld AJ. Low back pain in the United States: incidence and risk factors for presentation in the emergency setting. Spine J 2012;12:63-70.

22. Barrett-Connor E, Siris ES, Wehren LE, Miller PD, Abbott TA, Berger ML, Santora AC, Sherwood LM. Osteoporosis and fracture risk in women of different ethnic groups. J Bone Miner Res 2005;20:185-94.

23. Shin MH, Zmuda JM, Barrett-Connor E, Sheu Y, Patrick AL, Leung PC, Kwok A, Kweon SS, Nam HS, Cauley JA; Osteoporotic Fractures in Men (MrOS) Research Group. Race/ethnic differences in associations between bone mineral density and fracture history in older men. 
Osteoporos Int 2014;25:837-45.

24. Morin SN, Berger C, Liu W, Prior JC, Cheung AM, Hanley DA, Boyd SK, Wong AKO, Papaioannou A, Rahme E, Goltzman D; CaMos Research Group. Differences in fracture prevalence and in bone mineral density between Chinese and White Canadians: the Canadian Multicentre Osteoporosis Study (CaMos). Arch Osteoporos 2020;15:147.

25. Dennison E, Yoshimura N, Hashimoto T, Cooper C. Bone loss in Great Britain and Japan: a comparative longitudinal study. Bone 1998;23:379-82.

26. Sheu Y, Cauley JA, Wheeler VW, Patrick AL, Bunker $\mathrm{CH}$, Ensrud KE, Orwoll ES, Zmuda JM; Osteoporotic Fracture in Men (MrOS) Research Group. Age-related decline in bone density among ethnically diverse older men. Osteoporos Int 2011;22:599-605.

27. Lau EM, Lee JK, Suriwongpaisal P, Saw SM, Das De S, Khir A, Sambrook P. The incidence of hip fracture in four Asian countries: the Asian Osteoporosis Study (AOS). Osteoporos Int 2001;12:239-43.

28. Cheung CL, Ang SB, Chadha M, Chow ES, Chung YS, Hew FL, Jaisamrarn U, Ng H, Takeuchi Y, Wu CH, Xia W, Yu J, Fujiwara S. An updated hip fracture projection in Asia: The Asian Federation of Osteoporosis Societies study. Osteoporos Sarcopenia 2018;4:16-21.

29. Ballane G, Cauley JA, Luckey MM, El-Hajj Fuleihan G. Worldwide prevalence and incidence of osteoporotic vertebral fractures. Osteoporos Int 2017;28:1531-42.

30. Wáng YXJ, Xiao BH, Su Y, Leung JC, Lam PM, Kwok TC. Fine-tuning the cutpoint T-score as an epidemiological index with high specificity for osteoporosis: methodological considerations for the Chinese population. Quant Imaging Med Surg 2022;12:882-5.

Cite this article as: Wáng YXJ. Fragility fracture prevalence among elderly Chinese is no more than half of that of elderly Caucasians. Quant Imaging Med Surg 2022;12(2):874-881. doi: 10.21037/qims-21-876
31. Rapp K, Büchele G, Dreinhöfer K, Bücking B, Becker C, Benzinger P. Epidemiology of hip fractures : Systematic literature review of German data and an overview of the international literature. Z Gerontol Geriatr 2019;52:10-6.

32. Saad RK, Harb H, Bou-Orm IR, Ammar W, El-Hajj Fuleihan G. Secular Trends of Hip Fractures in Lebanon, 2006 to 2017: Implications for Clinical Practice and Public Health Policy in the Middle East Region. J Bone Miner Res 2020;35:71-80.

33. Gong XF, Li XP, Zhang LX, Center JR, Bliuc D, Shi Y, Wang HB, He L, Wu XB. Current status and distribution of hip fractures among older adults in China. Osteoporos Int 2021;32:1785-93.

34. Burge R, Dawson-Hughes B, Solomon DH, Wong JB, King A, Tosteson A. Incidence and economic burden of osteoporosis-related fractures in the United States, 2005 2025. J Bone Miner Res 2007;22:465-75.

35. Jones G, Nguyen T, Sambrook PN, Kelly PJ, Gilbert C, Eisman JA. Symptomatic fracture incidence in elderly men and women: the Dubbo Osteoporosis Epidemiology Study (DOES). Osteoporos Int 1994;4:277-82.

36. Wáng YXJ, Che-Nordin N, Deng M, Leung JCS, Kwok AWL, He LC, Griffith JF, Kwok TCY, Leung PC. Osteoporotic vertebral deformity with endplate/cortex fracture is associated with higher further vertebral fracture risk: the Ms. OS (Hong Kong) study results. Osteoporos Int 2019;30:897-905.

37. Kanis JA. Assessment of fracture risk and its application to screening for postmenopausal osteoporosis: synopsis of a WHO report. WHO Study Group. Osteoporos Int 1994;4:368-81.

38. Faulkner KG. The tale of the T-score: review and perspective. Osteoporos Int 2005;16:347-52. 